\title{
FORMER OF TURN TRAJECTORY OF SLIDING VALVE SHAFT OF GAS LINE
}

\author{
Vladislav.Yu. Dementyev ${ }^{1}$, Nikolay.V. Gusev ${ }^{2, *}$, Nikolay.V. Koyain ${ }^{2}$, and Sergey.Yu. \\ Shiryaev $^{2}$ \\ ${ }^{1}$ The $1^{\text {st }}$ category expert of production-technical management, OOO "Gazprom transgaz Tomsk", \\ 634000, Tomsk, Russia \\ ${ }^{1}$ Tomsk Polytechnic University, 634050, Tomsk, Russia
}

\begin{abstract}
Former of turn trajectory of sliding valve shaft of gas line, that allows to provide desired motion trajectory of sliding valve and its full closing, is considered in that paper. Imitation model of that former, research results, which allow to detect influence of gain factor and time constant of posi-tion controller on value of speed error, that has impact on delay of output coordinate from setting, and that results to delay of sliding valve motion process to setting position point, are shown.
\end{abstract}

\section{Introduction}

Gases flow controlling is maintained by changing of production of gas-compressor unit (GCU) [1]. Gas turbine plants (GTPs) or electrical machines (EMs) are used as drive of GCU. For new designed gas-compressor station (GCS), problem of GCU type choice should be solved with obligatory consideration of factors such as: high efficiency, reliability and high durability, maintenance simplicity and even ability of creation of nonmaintainable electric-drive units, ecological cleanness, wide regulation range. Using of regulated electric drive is economically right especially at objects, that have irregular load traffic, GTPs truly can't work with loads less critical. For rotation frequency regulated EMs, "surging" limits are reduced. Due to this, it is necessary to consider that implementation of regulated electric drives to GCS is the 1st step on the way to automation of all gas-transport system.

\section{Concept headings}

However, choice of application of frequency-regulated electric drive (FRED) was made, because FRED is the most economically effective with using of main gas-line, that work in variable technological modes of gas transit. The aim of this paper is development and researching of former of steering trajectory of sliding valve shaft of gas line. Electric drive of sliding valve is difficult multiple-loop structure of automatic regulation, that closes on position. The scheme incudes frequency-regulated electric drive, that based on KEB ST90

\footnotetext{
*Corresponding author: gusev@tpu.ru
} 
MB type induction motor, that has nominal rotating speed; position sensor with gain factor, that installed on mechanism, and position controller with transfer function [2, 3]. To provide soft trajectory of sliding valve motion, it is neces-sary to limit not only value of maximal steering speed, and accelerate. It can be provided by application of preferred trajectory former of motion, by way of application of power-up sensor with S-characteristic is preferred $[4,5,9,10]$. Characteristic and imitation model scheme of that former are shown on figure 1 .

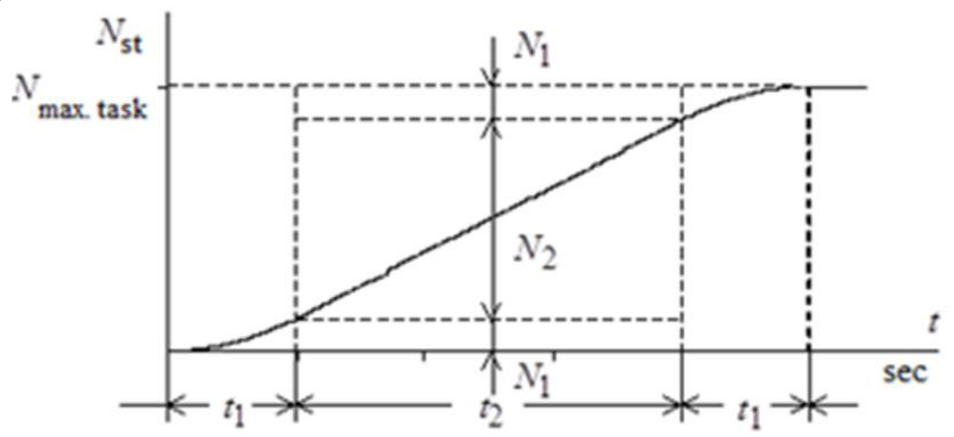

a)

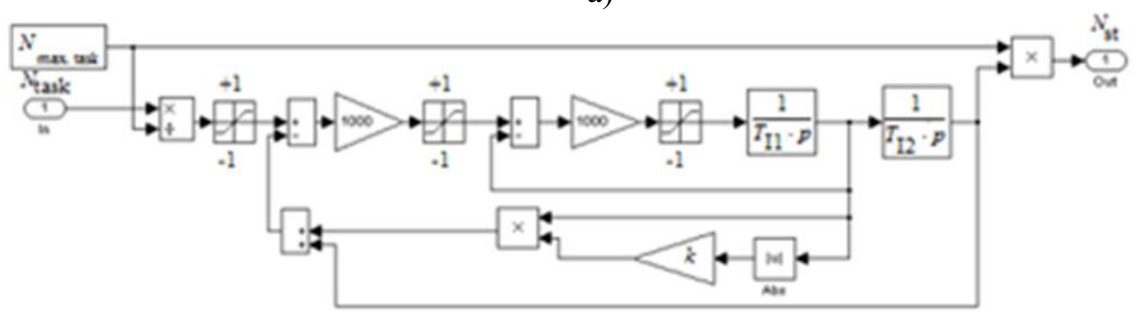

b)

Fig. 1. Power-up sensor with S-characteristic: $a$ - transient function; $b$ - imitation model.

Preferences of optimal steering trajectory of sliding valve are defined from following equations:

$$
t_{1}=t_{3}=\frac{\omega_{\max }}{\left(\frac{d \omega}{d t}\right)_{\max }}, \sec
$$

Where $\omega_{\max } \leq 209.4 \mathrm{rad} / \mathrm{sec}$ - used value of maximal rotation speed of motor with refining of given turn angle of sliding valve, $\mathrm{rad} / \mathrm{sec}$;

$$
\left(\frac{d \omega}{d t}\right)_{\max } \text { - used maximal value angular acceleration of motor with refining of given }
$$

turn angle of sliding valve, $\mathrm{rad}^{2} / \mathrm{sec}$;

$$
t_{2}=\frac{N_{\max }}{k \cdot k \cdot \omega_{\max }}-t_{1}=\frac{\varphi_{\max }}{k \cdot \omega_{\max }}-t_{1}, \sec , 1
$$

Where $\varphi_{\max } \leq \frac{21600}{4}=5400$ ang. $\min$. 
For setting of trajectory former, following quantity values are used:

$N_{\max }=10000$ discrete; $\varphi_{\max }=5400$ ang. min.

$\omega_{\max }=52.35 \mathrm{rad} / \mathrm{sec} ; \mathrm{t}_{1}=\mathrm{t}_{3}=0.2 \mathrm{sec}$, that is considered of maximal value of angular acceleration

$$
\left(\frac{d \omega}{d t}\right)_{\max }=\frac{\omega_{\max }}{t_{2}}=\frac{52.35}{0.2}=261.75 \frac{\mathrm{rad}^{2}}{\mathrm{sec}} .
$$

Then additional preferences of former setting are:

$$
\begin{gathered}
t_{2}=\frac{N_{\max }}{k \cdot k \cdot \omega_{\max }}-t_{1}=\frac{10000}{1.3222 \cdot 1.85185 \cdot 52.35}-0.2=41.9283 \mathrm{sec} ; \\
k=0.5 \cdot \frac{t_{1}}{t_{1}+t_{2}}=0.5 \cdot \frac{0.2}{41.9283+0.2}=0.0023737
\end{gathered}
$$

Researches were organized with task refining $\mathrm{N}_{\mathrm{t}}=200$ discrete, that is considered to problem

$$
\varphi_{t}=\frac{N_{t}}{k}=\frac{200}{1.85185}=108 \text { ang. } \min
$$

Transients in servo drive with P-position controller with task refining $\mathrm{N}_{\mathrm{t}}=200$ discrete $\left(\phi_{\mathrm{t}}=108\right.$ angular minutes) are shown on figures $2 \mathrm{a}, \mathrm{b}$.

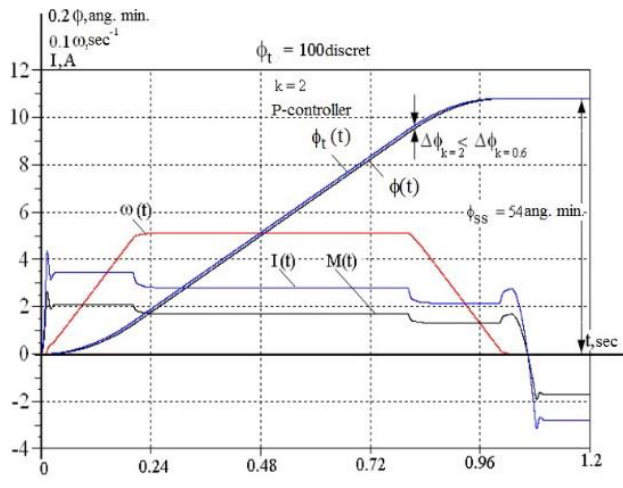

a)

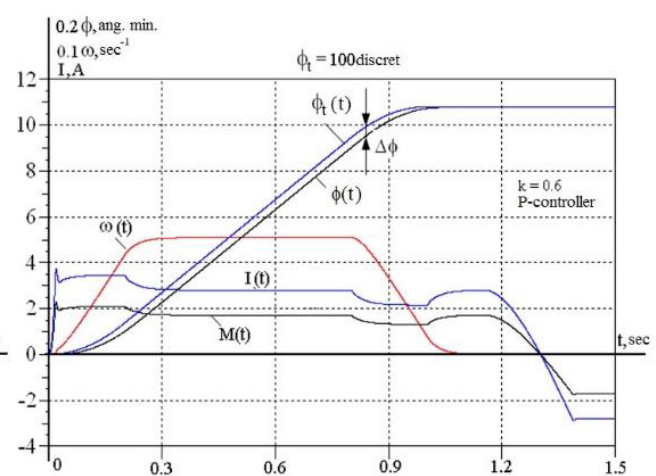

b)

Fig. 2. The process of task refining a) $\mathrm{N}_{t}=200$ discrete with P-position controller $\left(\mathrm{k}_{\mathrm{pc}}=0.6\right)$; b) $\mathrm{N}_{t}=200$ discrete with P-position controller $\left(\mathrm{k}_{\mathrm{pc}}=2\right)$.

\section{Experimental results}

It will be seen from figure $2 \mathrm{a}$, that velocity compensation $\Delta \varphi$ exists with refining of given motion trajectory of sliding valve shaft in system with $\mathrm{P}$-controller. The value of velocity compensation depends on chosen values of gain factor of P-position controller (figure $2 b$ ) and on maximal steering speed. Gain factor of controller is chosen on provide single sided approach of sliding valve to last spot of position, that is very important for its full closed. For this reason, gain factor of position controller can not be high and so velocity compensation can be serious with choice of maximal speed. That compensation leads to delay of output values to task and can be not preferred [6, 7, 8, 9]. Full elimination of velocity compensation is provided by application of PI-position controller. Curves of 
refining process of given motion trajectory of sliding valve shaft with PI-position controller are shown in figures $3 \mathrm{a}$ and $\mathrm{b}$.

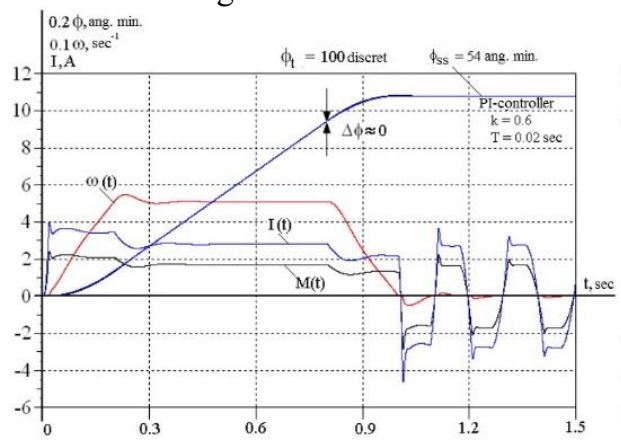

a)

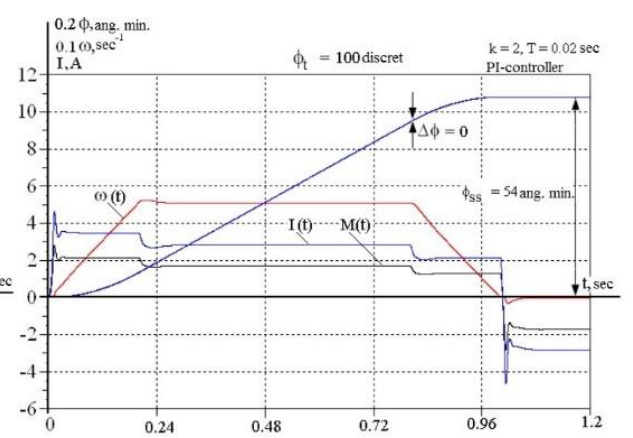

b)

Fig. 3. Process of task refining: a) $\mathrm{N}_{\mathrm{t}}=200$ discrete with PI-position controller ( $\mathrm{k}_{\mathrm{pc}}=2, \mathrm{~T}_{\mathrm{pc}}=0.02 \mathrm{sec}$ ); b) $\mathrm{N}_{\mathrm{t}}=200$ discrete with PI-position controller $\left(\mathrm{k}_{\mathrm{pc}}=0.6, \mathrm{~T}_{\mathrm{pc}}=0.02 \mathrm{sec}\right)$.

\section{Conclusion}

As it appears from figures $3 \mathrm{a}$ and $\mathrm{b}$, required character of electric drive motion of sliding valve and its way to position point are achieved by choice of parameters values of PIcontroller settings: Gain factor and time constant.

\section{References}

1. F. M. Mustafin, Pipeline rebar. Studying edition for university (Ufa, 2007) [in Russian]

2. Yu. N. Dementyev, Fundamentalynie issledovaniya, 12, 931 (2014) [in Russian]

3. Yu. N. Dementyev, A. D. Bragin, N. V. Koyain, L. S. Udut, 2015 International Siberian Conference on Control and Communications, 1, (2015)

4. Yu. N. Dementyev, K. N. Negodin, N. V. Koyain, L. S. Udut, Elektromehanika 4, 49 (2016) [in Russian]

5. A. Yu. Chernishev, Yu. N. Dementyev, I. A. Chernishev, AC electric drive (Tomsk Polytechnic University, 2015) [in Russian]

6. I. G. Odnokopylov, Y. N. Dementyev, I. V. Usachyov, D. Y. Lyapunov, A. S. Petrusyov, 2015 International Siberian Conference on Control and Communications (SIBCON): proceedings, 1 (2015)

7. L. S. Udut, O. P. Malyceva, N. V. Koyain, Design and research of automatic electric drives 8 (Tomsk Polytechnic University, Tomsk, Russia, 2014) [in Russian]

8. E. V. Bolovin, A. S. Glazyrin, V. N. Brendakov, 2015 International Siberian Conference on Control and Communications (SIBCON): proceedings, 1, (2015)

9. R. Yu. Tkachuk, A. S. Glazyrin, V. I. Polichshuk, 7th International Forum on Strategic Technology, 2, 586 (2012)

10. V. I. Polishchuk, V. L. Sergeev, Journal of Siberian Federal University. Mathematics \& Phisics, 8 (2), 201 (2015) 